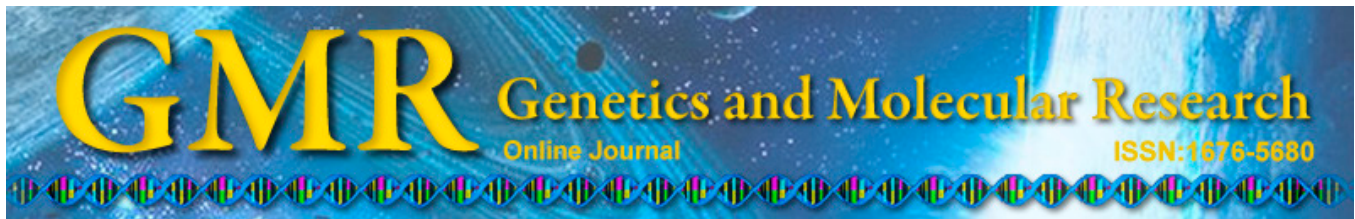

\title{
Influence of plasma exchange on transplantation related immune function in patients with liver failure
}

\author{
Y.M. Huo ${ }^{1 *}$, C.C. $\mathrm{Zhu}^{2 *}$, T.F. $\mathrm{Lu}^{3}$ and R. Hua ${ }^{1}$ \\ ${ }^{1}$ Department of Biliary-Pancreatic Surgery, Ren Ji Hospital, \\ School of Medicine, Shanghai Jiao Tong University, Shanghai, China \\ ${ }^{2}$ Department of General Surgery, Ren Ji Hospital, School of Medicine, \\ Shanghai Jiao Tong University, Shanghai, China \\ ${ }^{3}$ Department of Hepatic Surgery, Ren Ji Hospital, School of Medicine, \\ Shanghai Jiao Tong University, Shanghai, China \\ *These authors contributed equally to this study. \\ Corresponding author: R. Hua \\ E-mail: 13611657722@sina.cn
}

Genet. Mol. Res. 14 (3): 8170-8180 (2015)

Received August 5, 2014

Accepted February 19, 2015

Published July 27, 2015

DOI http://dx.doi.org/10.4238/2015.July.27.5

\begin{abstract}
This study aimed to evaluate the influence of plasma exchange (PE) treatment of patients with liver failure on the patient's immune function, including peripheral blood $\mathrm{T}$ lymphocytes and cytokines. Patients accepting PE for liver failure from October 2011 to February 2012 were included prospectively in the research group. Peripheral blood samples were collected at set time points. The percentages of $\mathrm{T}$ lymphocyte subtypes were detected by flow cytometry using different fluorescence labels including CD3-FITC, CD4-PerCP, CD8-PE, CD25-FITC, and Foxp3-PE. Changes in serum IL-17 concentration were followed by ELISA. In all fifteen patients who accepted $\mathrm{PE}$, the percentages of $\mathrm{CD}^{+}$and $\mathrm{CD}^{+} \mathrm{T}$ cells increased immediately after the procedure and then reduced gradually. These significant changes were confirmed by statistical analysis $(\mathrm{P}<0.05)$.
\end{abstract}


The percentage of $\mathrm{CD}^{+} \mathrm{T}$ cells also increased after PE to a certain extent, but failed to show statistical significance. The positive ratio of $\mathrm{CD}^{+} \mathrm{CD} 25^{+} \mathrm{Foxp}^{+} \mathrm{T}$ cells (Treg) increased after the treatment with statistical difference $(\mathrm{P}<0.05)$. The concentration of IL-17 in patient serum increased significantly following $\mathrm{PE}$ treatment $(\mathrm{P}<0.05)$. These results demonstrated that $\mathrm{T}$ lymphocyte subgroups of patients with liver failure could be influenced after PE treatment, and that cellular immunity could be recovered. PE treatment, therefore, can be viewed as providing reliable protection for the reconstruction of the patient immune system.

Key words: Artificial liver; Plasma exchange; Cellular immunity; $\mathrm{CD}^{+} \mathrm{CD} 25^{+}$regulatory T cells; Interleukin-17

\section{INTRODUCTION}

An artificial liver support system (ALSS) is an external device that can simulate, in part, the functions of a normal liver. Over the past 10 years, ALSS has emerged as an exciting tool for the treatment of chronic and acute liver failure with promising results. Compared with traditional conservative treatments, ALSS also to a large extent improves the prognosis and reduces the mortality of patients with severe hepatitis from liver failure. Plasma exchange (PE) is a relatively mature and popular method of ALSS treatment. PE plays an important role in the elimination of the in vivo toxins produced by patients with liver failure and improvement of their clinical symptoms. PE also leads to recovery of certain clinic functions, such as blood clotting profiles, and facilitates the environment required for hepatic regeneration and clinical recovery. Thus, ALSS is able to stabilize the patient with liver failure and purchase precious survival time pending future liver transplantation.

Abnormal immune function is an important factor involved in the pathogenesis of virus hepatitis and has vital impact on the progress of patients with liver failure. Liver failure, from various causes, is generally associated with immunologic disorders. These disorders lead to a breakdown of the inflammatory and anti-inflammatory network balance and cause variation in T lymphocyte subgroups, which can trigger the characteristic systemic inflammatory response syndrome. Furthermore, regional accentuation of immune functions can occur among patients with severe hepatitis or liver failure, which enhances the immune-mediated detrimental effects on target cells and produces high levels of damage to liver cells.

PE clears a wide range of toxin substance and can also influence immune function while adjusting the different cytokine concentrations in the circulation. In this study, we examined the changes in the percentages of T lymphocyte subgroups in patients with liver failure before and after PE treatment. Furthermore, the variance in the plasma concentration of interleukin-17 (IL-17), a cytokine relevant to hepatitis, was measured as well to evaluate the influence of $\mathrm{PE}$ on immune function.

\section{MATERIAL AND METHODS}

\section{Research objective and clinical profiles}

All 15 patients who participated in this research study were in-patients of the Depart- 
ment of General Surgery and Gastroenterology of Renji Hospital, School of Medicine, Shanghai Jiao Tong University from October 2011 to February 2012. Among them, eight had been diagnosed with chronic and severe hepatitis B virus infection; five were liver failure patients with recurrent hepatitis B infection after liver transplantation; and two had been diagnosed with early-stage obstructive liver injury following their liver transplantation operations. Thirteen of the patients were men and two were women, and their ages ranged from 34 to 48 years old with an average of 39.6 years. The conventional medical treatments for these patients included bed rest, nutritional supplements, maintenance of the water-electrolyte and acid-base balance, provision of serum-albumin and hepatocyte growth-promoting factors, glutathione reduction, emictory and dehydrant procedures, etc. The seven patients who had received liver transplantation operations also received immunosuppressive drug therapies, primarily the administration of Tacrolimus (FK 506, Prograf, Astellas Co., Ltd., Ireland), CellCept (Roche Pharmaceuticals, Switzerland), and methylprednisolone. Specifically, the treatment incorporated a triple therapy: Prograf, with an initial dose of $1 \mathrm{mg}$, administered twice daily; CellCept ( $1.0 \mathrm{~g}$, twice daily); and methylprednisolone (500 mg administered intravenously during the operation, followed by $200 \mathrm{mg}$ orally on the first day, $160 \mathrm{mg}$ on the second day, and dosage with daily reduction to $20 \mathrm{mg}$ on the sixth day after the operation). The dosage of all drugs was monitored and adjusted according to the drug blood level after the operation. The Child-Pugh score of disease severity was $\mathrm{B}$ for two of the 15 patients, and $\mathrm{C}$ for the remaining 13 . Four patients had evident abdominal dropsy, and four patients had an associated level 2-3 hepatic encephalopathy. A further four patients had associated hepatorenal syndrome. The drug blood levels of FK 506 were $5-8 \mathrm{ng} / \mathrm{mL}$ among the five patients with recurrent hepatitis B after the transplantation operation, and 3.0 and $3.5 \mathrm{ng} / \mathrm{mL}$ for the two patients with early-stage obstructive liver injury, respectively. The PE procedure was performed utilizing the fourth generation KPS8800CE artificial liver therapeutic apparatus, produced by Kuraray Co., Ltd. (Tokyo, Japan). The venous channel was arranged through femoral vein puncture to form the extracorporeal circulation. Blood was drawn out of the patient and the plasma was separated and abandoned. Fresh plasma was introduced through another path and mixed with the separated blood cells, and the mixed substance was returned into the patient. The in-out balance was strictly controlled. The PE procedure lasted for $1.5-2 \mathrm{~h}$, and the total plasma exchanged was $2000 \mathrm{~mL}$ with a blood flow of $100 \mathrm{~mL} / \mathrm{min}$.

\section{Specimen collection, preparation, and analysis}

Peripheral blood $(2 \mathrm{~mL})$ was collected during the following periods for analysis of T-lymphocytes: before and immediately following the PE treatment, and 1 and 2 days after the treatment. The blood was stored in anticoagulation tubes and sent to the Digestive Department Research Institute Laboratory at Renji Hospital for specimen preparation. The counts of $\mathrm{CD}^{+} \mathrm{T}$ cells, $\mathrm{CD} 4^{+} \mathrm{T}$ cells and $\mathrm{CD} 8^{+} \mathrm{T}$ cells in peripheral blood were determined by flow cytometry (Beckman Coulter, USA) using specific monoclonal antibodies (Beckman Coulter), respectively. The samples were processed within $6 \mathrm{~h}$ after they were obtained. Isotype control-stained cells were also prepared. Data were analyzed by Cytomics FC500 (Beckman Coulter). The expression of intracellular Forkhead box P3 (FOXP3) was detected using a PEconjugated anti-human FOXP3 staining kit (e-Bioscience) according to manufacturer instructions (Kobayashi et al., 2012). 
In addition, a second sample of $5 \mathrm{~mL}$ peripheral blood was collected at each time period for IL-17 detection. The serum was separated immediately and stored in a $-80^{\circ} \mathrm{C}$ freezer. An FACStar Plus flow cytometer by Beckton Dickinson (Bedford, MA, USA) was used for detection and the FACSDIVA program (Beckton Dickinson) was used for analysis. The double-antibody sandwich ABC-ELISA method was adopted to detect IL-17 serum concentrations (Zhang et al., 2012).

\section{Statistical analysis}

The professional SPSS 15.0 statistics software (SPSS, Chicago, IL, USA) was utilized for statistical analysis. The paired $t$-test was used to compare three pairs of data: the biochemical indices, the T lymphocyte percentages, and the serum IL-17 concentrations, before and after PE treatment, respectively. The Fisher test was used to compare the positive rates of $\mathrm{CD} 4^{+} \mathrm{CD} 25^{+} \mathrm{Foxp} 3^{+}$ T lymphocyte before and after PE treatment. Statistical significance was set as $\mathrm{P}<0.05$.

\section{RESULTS}

\section{Effects of PE treatment on clinical measures}

Among the 15 patients who received PE treatment, five improved, eight died, and two left the hospital with unavailable follow-up. Before the treatment, the Child-Pugh scores for patients 1 and 2 were $\mathrm{B}$, and the rest of the patients were scored at $\mathrm{C}$. Among the main biochemical changes following PE treatment, alanine aminotransferase, total bilirubin, albumin, and prothrombin time noticeably decreased $(\mathrm{P}<0.01)$, whereas creatinine had no noticeable change, as shown in Table 1. Patients 1 to 7 received (orthotopic) liver transplantations. Among these, patients 1 and 2 presented early-stage obstructive liver injury following liver transplantation, and the remaining five patients were diagnosed liver failure with recurrent hepatitis B after liver transplantations. All seven patients were affected by primary cirrhosis decompensation secondary to hepatitis B, and one patient was diagnosed with liver cancer.

\begin{tabular}{|c|c|c|c|c|c|c|c|c|c|c|}
\hline \multirow[t]{3}{*}{ ID } & \multicolumn{10}{|c|}{ Plasma exchange } \\
\hline & \multicolumn{2}{|c|}{$\operatorname{ALT}(\mathrm{IU} / \mathrm{L})$} & \multicolumn{2}{|c|}{ Tbil $(\mu \mathrm{M})$} & \multicolumn{2}{|c|}{$\mathrm{Alb}(\mathrm{g} / \mathrm{L})$} & \multicolumn{2}{|c|}{$\mathrm{PT}(\mathrm{s})$} & \multicolumn{2}{|c|}{$\mathrm{Cr}(\mu \mathrm{M})$} \\
\hline & Before & After & Before & After & Before & After & Before & After & Before & After \\
\hline 1 & 119 & 68 & 735.9 & 687.4 & 24 & 25 & 15.4 & 12 & 39 & 54 \\
\hline 2 & 83 & 53 & 762.2 & 681.6 & 26 & 28 & 14.4 & 13.3 & 38 & 44 \\
\hline 3 & 37 & 41 & 775.8 & 649.9 & 27 & 31 & 17 & 15.1 & 12 & 11 \\
\hline 4 & 48 & 36 & 635.6 & 555.3 & 27 & 29 & 14.1 & 14 & 9 & 36 \\
\hline 5 & 47 & 36 & 661.7 & 443.3 & 29 & 31 & 28.1 & 21.3 & 157 & 93 \\
\hline 6 & 120 & 66 & 515.5 & 311.3 & 27 & 28 & 22.2 & 18 & 31 & 57 \\
\hline 7 & 89 & 48 & 494.1 & 295.1 & 29 & 28 & 23.8 & 13.2 & 32 & 69 \\
\hline 8 & 91 & 56 & 479.2 & 321.2 & 25 & 26 & 25.6 & 16.9 & 37 & 67 \\
\hline 9 & 105 & 49 & 514.3 & 297.8 & 22 & 30 & 31 & 14.8 & 71 & 67 \\
\hline 10 & 50 & 11 & 826.7 & 480.8 & 27 & 27 & 32.7 & 23.5 & 276 & 233 \\
\hline 11 & 42 & 28 & 589.9 & 399.5 & 28 & 27 & 29.5 & 20.8 & 247 & 241 \\
\hline 12 & 36 & 23 & 647.6 & 356.2 & 27 & 29 & 34.5 & 18.4 & 263 & 225 \\
\hline 13 & 124 & 119 & 784.4 & 678.4 & 22 & 24 & 27.6 & 20.1 & 156 & 257 \\
\hline 14 & 126 & 90 & 857.5 & 615.6 & 24 & 28 & 28.5 & 16.1 & 242 & 226 \\
\hline 15 & 83 & 50 & 762.2 & 635.5 & 26 & 27 & 26.1 & 15.3 & 44 & 32 \\
\hline
\end{tabular}

$\mathrm{ALT}=$ alanine aminotransferase; $\mathrm{Tbil}=$ total bilirubin; $\mathrm{Alb}=$ albumin; $\mathrm{PT}=$ prothrombin time; $\mathrm{Cr}=$ creatinine; $\mathrm{PE}=$ plasma exchange. 
Both of the patients with obstructive liver injury had deepening jaundice and increasing serum bilirubin, alkaline phosphatase, and gamma glutamyl transferase indices 1 week after the liver transplantation. The conventional immunosuppressive triple therapy prescription for these two patients after the operation included: Prograf, with an initial dose of $2 \mathrm{mg} / \mathrm{day}$ (1 $\mathrm{mg}$, twice daily), CellCept (1.0 g, twice daily), and methylprednisolone (500 $\mathrm{mg}$ administered intravenously during the operation, and $200 \mathrm{mg}$ orally for the first day, $160 \mathrm{mg}$ for the second day, and reduced dosages daily until $20 \mathrm{mg}$ was administered on the sixth day after the operation). The drug blood level of Tacrolimus was kept within 3.0 to $5.0 \mathrm{ng} / \mathrm{mL}$. A liver puncture biopsy was conducted on these two patients to exclude transplantation-associated rejection and liver ischemia. Before the PE treatment, an endoscopic retrograde cholangeopancreatogram was used to drain the biliary tract. Glutathione reduction, and hepatocyte growth-promoting factors, ursodeoxycholic acid, and interferon treatments were also used. Both patients had gradually decreasing serum bilirubin level after the treatment and they recovered and left the hospital within 2 months.

For the five patients with recurrent hepatitis B infection, liver failure occurred during the 3 to 6 years following the liver transplant operation. After the operation, conventional immunosuppressive treatments were administered and the immunosuppressive prescription was the same as that for the patients with obstructive liver injury. Tacrolimus was kept within 5.0 to $8.0 \mathrm{ng} / \mathrm{mL}$. After the transplantation, interferon treatment was performed and anti-hepatitis B immunoglobulin was injected twice a week. In the hospital, an increasing serum biliary index was still observed in patients following glutathione reduction and treatments with hepatocyte growth-promoting factors, serum albumin, and nutritional supplements. Patients exhibited different levels of abdominal dropsy, no hepatic encephalopathy, and Child-Pugh scores of C. After the PE treatment, the chief complaints by patients were requests for alleviation of abdominal distention, and improvement of various biochemical indices. The biochemical index of one patient improved after the PE treatment; while the indices regressed again shortly after treatment for the other four patients and they eventually died from liver failure.

\section{Effects of PE treatment on T lymphocyte subgroup percentages}

Among the 15 patients having undergone $\mathrm{PE}$ treatment, the $\mathrm{CD} 3^{+} \mathrm{T}$ and $\mathrm{CD} 8^{+} \mathrm{T}$ cell percentages markedly increased on the day immediately following the treatment. Thereafter, the percentages gradually decreased and the differences were statistically significant $(\mathrm{P}<0.05)$ beginning at the second day after the operation. The $\mathrm{CD}^{+} \mathrm{T}$ percentages also increased to varying degrees after the PE treatment but did not reach significance (Table 2). Statistically significance was observed, however, for the $\mathrm{CD} 4^{+} \mathrm{CD} 25^{+} \mathrm{Foxp}^{+} \mathrm{T}$ lymphocyte (Treg)-positive ratio (before $v s$ after the $\mathrm{PE}$ treatment, $\mathrm{P}<0.05$ ). The Treg percentage itself decreased after

Table 2. Percentage changes in T lymphocytes before and after PE treatment.

\begin{tabular}{llllc}
\hline & Before PE & After PE & 1 day after PE & 2 days after PE \\
\hline $\mathrm{CD}^{+} \mathrm{T}(\%)$ & $62.35 \pm 12.67^{*}$ & $70.03 \pm 9.89$ & $60.24 \pm 25.64$ & $56.20 \pm 17.97^{*}$ \\
$\mathrm{CD}^{+} \mathrm{T}(\%)$ & $37.90 \pm 15.00^{*}$ & $41.74 \pm 16.92$ & $34.07 \pm 20.29$ & $32.17 \pm 13.16^{*}$ \\
$\mathrm{CD} 8^{+} \mathrm{T}(\%)$ & $29.92 \pm 6.64$ & $33.69 \pm 6.15$ & $29.69 \pm 11.96$ & $29.56 \pm 7.91$ \\
\hline
\end{tabular}

$\mathrm{PE}=$ plasma exchange. $*$ Compared with values after $\mathrm{PE}, \mathrm{P}<0.05$. The values are reported as means \pm standard deviation. 
PE treatment, but not to a statistically significant degree (Table 3). Typical results are shown in Figures 1 and 2 and the data are summarized in Figure 3.

Table 3. $\mathrm{CD}^{+}{ }^{+} \mathrm{CD} 25^{+} \mathrm{Foxp}^{+} \mathrm{T}$ lymphocyte values after PE treatment.
\begin{tabular}{lcccc} 
& Before PE & After PE & 1 day after PE & 2 days after PE \\
\hline $\mathrm{CD}^{+} \mathrm{CD} 25^{+} \mathrm{Foxp}^{+} \mathrm{T}$ & $14 / 15$ & $7 / 15$ & $9 / 15$ & $12 / 15$ \\
$\mathrm{CD}^{+} \mathrm{CD} 25^{+} \mathrm{Foxp}^{+} \mathrm{T}$ & $8.93 \pm 7.69$ & $6.77 \pm 10.84$ & $8.21 \pm 15.21$ & $10.54 \pm 11.45^{*}$ \\
\hline
\end{tabular}

$\mathrm{PE}=$ plasma exchange. ${ }^{*}$ Compared with values after $\mathrm{PE}, \mathrm{P}<0.05$.
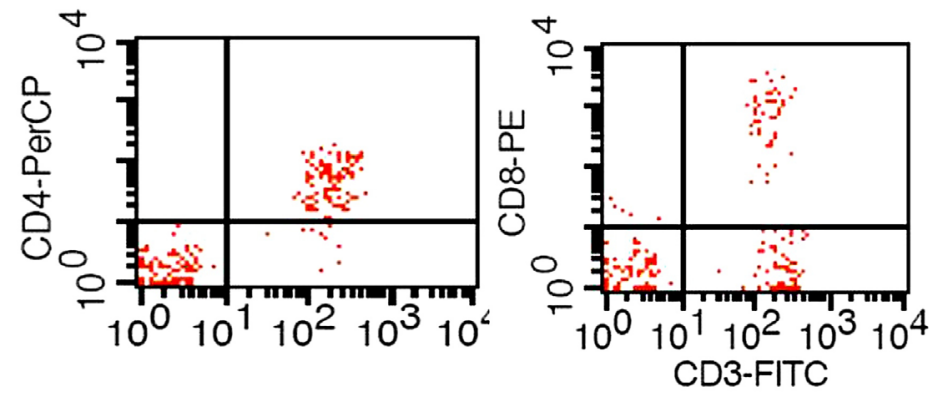

Figure 1. Flow cytometry detection results of $\mathrm{CD}^{+}, \mathrm{CD}^{+}$, and $\mathrm{CD}^{+} \mathrm{T}$ lymphocytes. $\mathrm{PerCP}=$ peridinin chlorophyll; $\mathrm{PE}=$ phycoerythrin $; \mathrm{FITC}=$ fluorescein isothiocyanate.
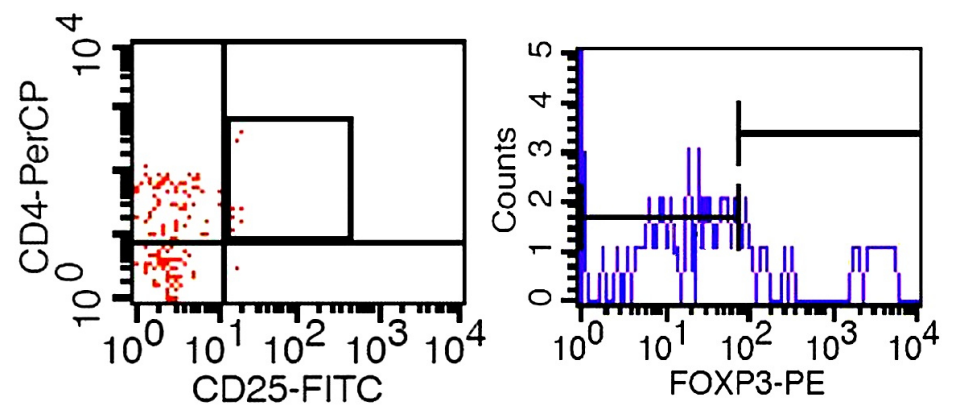

Figure 2. Flow cytometry detection results of $\mathrm{CD} 4^{+} \mathrm{CD} 25^{+} \mathrm{Foxp}^{+} \mathrm{T}$ lymphocytes. $\mathrm{PerCP}=$ peridinin chlorophyll; $\mathrm{PE}=$ phycoerythrin; FITC $=$ fluorescein isothiocyanate.

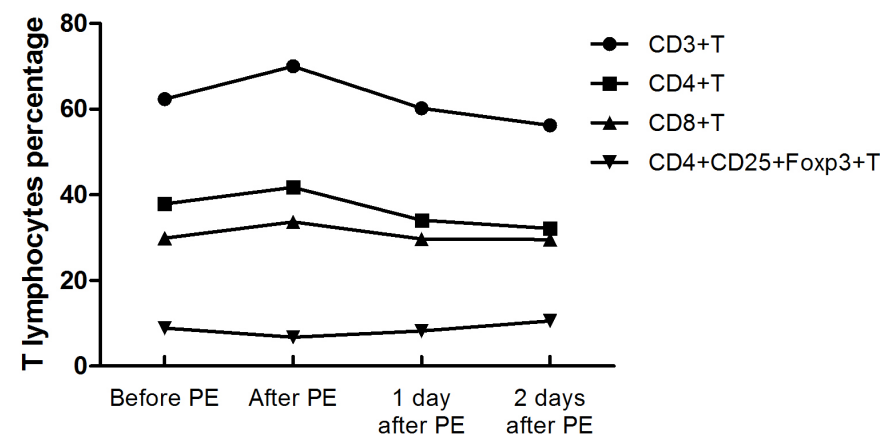

Figure 3. $\mathrm{T}$ cell subset changes before and after plasma exchange (PE). 


\section{Effects of PE treatment on serum IL-17 concentration}

The serum IL-17 concentration increased significantly immediately after PE treatment for all 15 patients $(\mathrm{P}<0.05)$. However, the variations in serum IL-17 concentrations for the 2 days after and immediately following the PE treatment were not significant (Table 4).

\begin{tabular}{|c|c|c|c|}
\hline & Before PE & After PE & 2 days after $\mathrm{PE}$ \\
\hline IL-17 (pg/mL) & $96.512 \pm 88.723 *$ & $175.512 \pm 135.877$ & $180.912 \pm 163.689$ \\
\hline
\end{tabular}

\section{DISCUSSION}

$\mathrm{PE}$ is a relatively mature and popular method of artificial liver treatment. Since this method clears off not only macro-molecular but also middle- and micro-molecular toxic substances, it clears a wide range of toxic substances and can also be used to adjust specific cytokine concentrations for patients with liver failure.

It has been demonstrated that cellular immune function is usually compromised in patients suffering from chronic liver disease compared with the normal population, and each of the $\mathrm{T}$ lymphocyte subgroup percentages such as $\mathrm{CD}^{+}, \mathrm{CD}^{+}$, and $\mathrm{CD} 8^{+} \mathrm{T}$ lymphocytes is lower than in the normal population. However, the percentage of Treg cells, a T lymphocyte subgroup with immune suppression characteristics, is higher than in the normal population. This indicates that the immune defect in liver disease is an important mechanism in invasion, protraction, and progression of virus hepatitis pathogenesis. Regional accentuation of immune function is also observed among patients with severe hepatitis or liver failure, which enhances the immune-mediated detrimental effects on target cells and produces high levels of damage to liver cells. Furthermore, the immune-pathological exchange of viral hepatitis is primarily accommodated by $\mathrm{T}$ cells. The function of $\mathrm{T}$ cells is double-sided: they can clear the virus or control its diffusion; on the other hand, they may exacerbate the disease through immunological injury as described above. Thus, PE treatment can influence the immune function of liver failure patients as well as clearing various toxic substances in the circulation.

$\mathrm{T}$ cell subsets, especially $\mathrm{CD} 4^{+}$and $\mathrm{CD} 8^{+} \mathrm{T}$ cells, have an important role in the regulation of immune response. $\mathrm{CD} 4^{+} \mathrm{T}$ cells are primarily helper $\mathrm{T}$ cells, which produce various cytokines that can cause delayed hypersensitivity, and can subsequently provoke apoptosis. $\mathrm{CD}^{+} \mathrm{T}$ cells are primarily cytotoxic T cells (CTLs). Cytotoxic activity mediated by CTLs is based on apoptosis through porforin or Fas pathways. CTLs are the major effect cell in clearing virus. In our study, the percentages of both $\mathrm{CD}^{+}$and $\mathrm{CD} 8^{+} \mathrm{T}$ cells significantly increased after PE $(\mathrm{P}<0.05)$. $\mathrm{CD} 4^{+} \mathrm{T}$ cells also increased after $\mathrm{PE}$ to some extent, but failed to reach statistical significance; this might be explained by an insufficient sample size. The ability of PE treatment to function in the normalization of $T$ cell subset percentages depended on its treatment principle; that is, to replace patient plasma with normal plasma. However, because of the development and progression of the disease, we demonstrated that the percentage of $\mathrm{T}$ cell subsets subsequently decreased, tending toward the pre-treatment state after the second day following PE treatment. 
Treg cells have recently become the "hot topic" in the immune-regulation research field. Treg cells are a class of T lymphocyte subset with immunosuppressive properties, which play an important role in regulating the peripheral immune response (Stephens et al., 2004). Immune tolerance, which is a basic activity along with immune activation, is an acquired characteristic. In contrast, in patients with liver failure, the immune reaction is too strong, and can cause serious injury to the target cells. Treg cells specifically express the transcription factor Foxp3, which therefore serves as a good marker to evaluate the immune state. Overall, regulatory T cells can be divided into two major categories: natural and acquired accommodation cells (Shevach, 2002). Treg belongs to the former. $\mathrm{CD} 4^{+} \mathrm{CD} 25^{+} \mathrm{T}$ cells are not definitively Tregs, but also include certain activated $\mathrm{CD}^{+} \mathrm{T}$ cells. Because of this, it is not sufficient to categorize Treg cells as those cells double positive for CD4 and CD25. Foxp3, however, is closely correlated with the differentiation and maturity of Tregs. Therefore, Foxp3 has been proposed as the golden standard for detecting Tregs (Jonuleit et al., 2001; Hori et al., 2003; Sakaguchi, 2004). Tregs might regulate the immune state in multiple ways, including: 1) After activation by TCR stimulation, Tregs suppress $\mathrm{CD} 4^{+}$and $\mathrm{CD} 8^{+} \mathrm{T}$ cells by the transcription and expression of IL-2, which interferes with the activation and proliferation of $\mathrm{CD}^{+}$and $\mathrm{CD} 8^{+}$ T cells (Coffer and Burgering, 2004; Martin et al., 2004). 2) Tregs secrete IL-10, TGF- $\beta$, and other immune suppression cell factors. These participate in the degenerative feedback regulatory mechanism and suppress the production of inflammation factors. 3) $\mathrm{CD} 4{ }^{+} \mathrm{CD} 25^{+}$Treg cells could reduce perforin, IFN- $\alpha$, and cytotoxic action (Trzonkowski et al., 2004). In our study, the numbers of T cells that were double positive for CD4 and CD25 generally increased following PE treatment. In order to more accurately detect the changes of Tregs, we incorporated the Foxp3-PE antibody as a marker on the surface of the cell nucleus through membrane rupture. Testing showed that the expression of Foxp 3 was reduced immediately following PE treatment, and gradually increased tending toward the pre-treatment state 2 days later. However, although the percentage of Tregs was reduced after PE treatment, it was still higher than normal.

Liver failure occurs because the human body produces an intensive immune reaction against the virus, which results in a large number of necrotic liver cells and the consequential failure of immune function. The high viral load in gravis type hepatitis B patients consumes a large number of $\mathrm{T}$ lymphocytes, which lowers the overall immune defense ability against infection. In our study, the value of PE treatment was generally in two ways: PE increased the percentage of $\mathrm{CD}^{+}, \mathrm{CD}^{+}$and $\mathrm{CD} 8^{+} \mathrm{T}$ cells, but decreased $\mathrm{CD} 4^{+} \mathrm{CD} 25^{+}$Tregs. This indicated that the cellular immune function had been promoted, which was useful for cleaning up virus. On the other hand, promotion of cellular immune function through PE could further injure target cells, and aggravate liver cell damage.

IL-17 is a new type of interleukin discovered in activated T lymphocytes by Zhengbing Yao of Imunnex, USA (Yao et al., 1997). Human IL-17 is a 32-kD molecular weight homodimer composed of 155 amino acids, and its $\mathrm{N}$ terminus is a signal polypeptide composed of 9-23 residues. The $I L-17$ locus is at chromosome $2 \mathrm{q} 31$, and $I L-17$ gene expression is under strict control. IL-17 is a powerful pre-inflammation factor, and is also a fine-tuning cytokine for inflammatory reactions. Fibroblast cells, keratinocytes, epithelial cells, and endothelial cells produce cytokines such as IL-6, IL-8, TNF- $\alpha$, PGE2, metalloprotease-1, and MCP-1 under stimulation of IL-17 (Nakae et al., 2003; Kolls and Linden, 2004). IL-17 can also induce fibroblast cells to express ICAM-1, and promote T cell proliferation. IL-17 has a synergistic effect on the enhancement of the inflammation reaction along with various cytokines. In vitro research has shown that IL-17, in cooperation with other pre-inflammation factors, can pro- 
mote the production of GM-CSF, IL-8, and IL-6 (Nakae et al., 2003; Kolls and Linden, 2004). It was initially thought that IL-17 was primarily produced by activated $\mathrm{CD} 4^{+}$memory $\mathrm{T}$ cells. However, it has since been found that $\mathrm{TCR}^{+} \mathrm{CD} 4 \mathrm{CD} 8$ - thymocytes, epithelial cells, and vascular endothelial cells also express IL-17 to different levels. In addition, when activated by cAMP or PKA pathways, CD8 ${ }^{+} \mathrm{T}$ cells express elevated levels of $I L-17 \mathrm{mRNA}$ (Yao et al., 1997). Upon production of IL-17, some immature CD4 $4^{+} \mathrm{T}$ cells in the thymus gland did not differentiate into Th1 or Th2 cells, but differentiated into Th17 cells instead. Th17 cells are another type of helper T cell that can produce IL-17 (Harrington et al., 2005; Langrish et al., 2005; Park et al., 2005). When Tregs are present, immature $\mathrm{CD}^{+} \mathrm{T}$ cells differentiate more often into Th17 instead of into Th1 or Th2 cells (Veldhoen et al., 2006). The mechanism of immature $\mathrm{CD}^{+} \mathrm{T}$ cells differentiation into Th17 cells is still unknown (Iwakura and Ishigame, 2006).

IL-17 also has the ability to recruit and activate neutrophils. In animal experiments, after $6 \mathrm{~h}$ stimulation of mouse airways by endotoxin, T cells produced a high level of soluble IL-17 in spleen and lung. This effective response required the participation of macrophages. Further study showed that IL-17 recruited neutrophils through induction of cell locomotion factors such as IL-6 and MIP-2 (Miyamoto et al., 2003). Furthermore, IL-17 was shown to be able to promote the growth and differentiation of hemopoietic progenitor cells, which might be related to the fact that IL-17 can stimulate the production of G-CSF, GM-CSF, and other downstream cytokines (Zou and Tam, 2002).

In our study, serum IL-17 concentrations increased significantly after PE treatment, although the mechanism is still unknown. A possible explanation could be that, because of immune activation mediated by variant plasma provided through PE treatment, cytokines such as IL-17 increase to a certain extent. Besides, the process of plasma separation will also make cytokines increase. These cytokines have a relatively short half-life but fast production, so that PE cannot get rid of them in time.

As has been often reported in the literature, PE can be used to modulate the serum concentrations of cytokines in patients with liver failure. Various kinds of inflammatory cell factors such as TNF- $\alpha$, IL-6, and IL-8 were cleared by PE (Iwai et al., 1998). However, the concentration of IL-17, as an upstream cell factor, increased significantly following PE. Since IL-17 could intensify T cell immunity when mediated by macrophages, the change in IL-17 concentration might impact liver failure patients in several ways: 1) in the state of immune functional disorder, patients have a high risk of infection; therefore, an enhancement of IL-17 might promote patient immunity, which might lead to a positive defense against the pathogen. 2) On the other hand, at the time of infection and the initiation of the inflammatory pathophysiological process, IL-17 might have played an important role in aggravation of the disease because of its ability to assemble and activate neutrophils. For example, Laan et al. (2002) studied 15 patients with serious pulmonary infection induced by confined exposure to swine. He found that the number of neutrophils increased 51-fold on average after a 2-h exposure as compared with the numbers present 2 weeks before infection, and that IL-17 in BALF increased to 26.9 from $<7.8 \mathrm{pg} / \mathrm{mL}$, a significant difference $(\mathrm{P}<0.05)$. In addition, it was found that injection of recombinant adenovirus encoding IL-17 into rat lung tissue led to IL-17 overexpression. This induced the assembly of a large number of neutrophils, elevated the clearance rate of Kelbsiella pneumoniae and thus increased the survival rate. However, when the inflammation caused by $K$. pneumoniae occurred, injection of IL-17 was found to have no effect, which the authors interpreted to mean that use of IL-17 might promote bacterial immunity, but only when performed at a suitable time(Ye et al., 2001). 
Recent studies have found that IL-17 participates in the allo-immunological rejection. Studies using an animal research model found that the concentrations of serum IL-17 and $I L$ 17 mRNA was raised 2 days after allogeneic kidney graft. In contrast, the IL-17 antigen has not been found around the kidney of normal people or in people that have not suffered immunological rejection. In patients with sub-clinical rejection, the level of $I L-17 \mathrm{mRNA}$ in their urinary mononuclear cells increased at the same time, suggesting that IL-17 could be used as sub-clinical allogeneic kidney transplant rejection early predictor (Hsieh et al., 2001). Furthermore, IL-17 is not only involved in the immune response following kidney transplantation, but is also very active following transplantation of other organs as well. The study found that the use of IL-17 antagonists could increase vascularization and survival following heart transplant (Booth and Bishop, 2010). However, the mechanism underlying the involvement of IL-17 in immune response after liver transplantation has not yet been reported.

ALPE treatment has been generally accepted as an effective mechanism, which provides good support for patients with liver failure. Its effect on improvement of clinical physiological and biochemical indicators has been widely demonstrated. Through the results from our research, we can summarize its transplant-related immune function as follows: after PE treatment, the counts of $\mathrm{CD}^{+}, \mathrm{CD}^{+}$, and $\mathrm{CD} 8^{+} \mathrm{T}$ cell subsets increased in patients, whereas at the same time the $\mathrm{CD} 4^{+} \mathrm{CD} 25^{+}$Treg cell count was reduced. In addition, the serum concentration of the pro-inflammatory factor IL-17 was significantly increased. These findings suggested that the patient immune function had been upgraded. However, due to disease progression, $\mathrm{T}$ cell subsets gradually declined, demonstrating that the immune function gradually returned to its pretreatment state. However, through the removal of a variety of endotoxins, immune complexes, and various inflammatory cytokines, PE provides a very important environment of stability and balance, and a reliable protection for the reconstruction of the patient immune system.

\section{Conflicts of interest}

The authors declare no conflict of interest.

\section{ACKNOWLEDGMENTS}

Research supported by grants from Young Medical Doctors Training and Funding Project of Shanghai Municipal Commission of Health and Family Planning.

\section{REFERENCES}

Booth AJ and Bishop DK (2010). TGF-beta, IL-6, IL-17 and CTGF direct multiple pathologies of chronic cardiac allograft rejection. Immunotherapy 2: 511-520.

Coffer PJ and Burgering BM (2004). Forkhead-box transcription factors and their role in the immune system. Nat. Rev. Immunol. 4: 889-899.

Harrington LE, Hatton RD, Mangan PR, Turner H, et al. (2005). Interleukin 17-producing CD4+ effector T cells develop via a lineage distinct from the T helper type 1 and 2 lineages. Nat. Immunol. 6: 1123-1132.

Hori S, Nomura T and Sakaguchi S (2003). Control of regulatory T cell development by the transcription factor Foxp3. Science 299: 1057-1061.

Hsieh HG, Loong CC, Lui WY, Chen A, et al. (2001). IL-17 expression as a possible predictive parameter for subclinical renal allograft rejection. Transpl. Int. 14: 287-298.

Iwai H, Nagaki M, Naito T, Ishiki Y, et al. (1998). Removal of endotoxin and cytokines by plasma exchange in patients with acute hepatic failure. Crit. Care Med. 26: 873-876. 
Iwakura Y and Ishigame H (2006). The IL-23/ IL-17 axis in inflammation. J. Clin. Invest. 116: 1218-1222.

Jonuleit H, Schmitt E, Stassen M, Tuettenberg A, et al. (2001). Identification and functional characterization of human CD4(+)CD25(+) T cells with regulatory properties isolated from peripheral blood. J. Exp. Med. 193: 1285-1294.

Kobayashi T, Nakatsuka K, Shimizu M, Tamura H, et al. (2012). Ribavirin modulates the conversion of human CD4(+) CD25(-) T cell to CD4(+) CD25(+) FOXP3(+) T cell via suppressing interleukin-10-producing regulatory T cell. Immunology 137: 259-270.

Kolls JK and Linden A (2004). Interleukin-17 family members and inflammation. Immunity 21: 467-476.

Laan M, Palmberg L, Larsson K and Lindén A (2002). Free, soluble interleukin-17 protein during severe inflammation in human airways. Eur. Respir. J. 19: 534-537.

Langrish CL, Chen Y, Blumenschein WM, Mattson J, et al. (2005). IL-23 drives a pathogenic T cell population that induces autoimmune inflammation. J. Exp. Med. 201: 233-240.

Martin B, Banz A, Bienvenu B, Cordier C, et al. (2004). Suppression of CD4+ T lymphocyte effector functions by CD4+CD25+ cells in vivo. J. Immunol. 172: 3391-3398.

Miyamoto M, Prause O, Sjöstrand M, Laan M, et al. (2003). Endogenous IL-17 as a mediator of neutrophil recruitment caused by endotoxin exposure in mouse airways. J. Immunol. 170: 4665-4672.

Nakae S, Saijo S, Horai R, Sudo K, et al. (2003). IL-17 production from activated T cells is required for the spontaneous development of destructive arthritis in mice deficient in IL-1 receptor antagonist. Proc. Natl. Acad. Sci. U. S. A. 100: 5986-5990.

Park H, Li Z, Yang XO, Chang SH, et al. (2005). A distinct lineage of CD4 T cells regulates tissue inflammation by producing interleukin 17. Nat. Immunol. 6: 1133-1141.

Sakaguchi S (2004). Naturally arising CD4+ regulatory T cells for immunologic self-tolerance and negative control of immune responses. Annu. Rev. Immunol. 22: 531-562.

Shevach EM (2002). CD4+ CD25+ suppressor T cells: more questions than answers. Nat. Rev. Immunol. 2: 389-400.

Stephens LA, Barclay AN and Mason D (2004). Phenotypic characterization of regulatory CD4+CD25+ T cells in rats. Int. Immunol. 16: 365-375.

Trzonkowski P, Szmit E, Mysliwska J, Dobyszuk A, et al. (2004). CD4+CD25+ T regulatory cells inhibit cytotoxic activity of T CD8+ and NK lymphocytes in the direct cell-to-cell interaction. Clin. Immunol. 112: 258-267.

Veldhoen M, Hocking RJ, Atkins CJ, Locksley RM, et al. (2006). TGFbeta in the context of an inflammatory cytokine milieu supports de novo differentiation of IL-17-producing T cells. Immunity 24: 179-189.

Yao Z, Spriggs MK, Derry JM, Strockbine L, et al. (1997). Molecular characterization of the human interleukin (IL)-17 receptor. Cytokine 9: 794-800.

Ye P, Garvey PB, Zhang P, Nelson S, et al. (2001). Interleukin-17 and lung host defense against Klebsiella pneumoniae infection. Am. J. Respir. Cell Mol. Biol. 25: 335-340.

Zhang XL, Zhang WH, Fan XH, Wei F, et al. (2012). Serum level of IL-17 in patients with multiple myeloma and its clinical significance. Zhongguo Shi Yan Xue Ye Xue Za Zhi 20: 930-932.

Zou GM and Tam YK (2002). Cytokines in the generation and maturation of dendritic cells: recent advances. Eur. Cytokine Netw. 13: 186-199. 